This is the accepted version of the article:

Carvalho, António (2021), "Rethinking the politics of meditation: Practice, affect and

ontology", The Sociological Review, 69(6), 1260-1276. DOI: $\underline{10.1177 / 00380261211029457}$

Published version available at:

https://doi.org/10.1177/00380261211029457

\title{
Rethinking the politics of meditation: Practice, affect and ontology
}

António Carvalho (Centre for Social Studies, University of Coimbra, Portugal)

\begin{abstract}
This article develops an ontological approach to study meditation in practice. Recognizing that social studies of meditation are dominated by critical and humanist standpoints, it suggests that the politics of meditation should not be indexed to hegemonic social forces - capitalism, neoliberalism, medicalization - but to what it can do to bodies, selves and environments through particular performances and engagements with nonhumans. In order to develop this argument, the article delves into two popular practices of meditation - Vipassana, in the tradition of S. N. Goenka, and Mindfulness, according to the teachings of Thich Nhat Hanh. The empirical data stem from fieldwork carried out between 2010 and 2013 in France, Portugal and the United Kingdom. Twenty-four semistructured interviews were conducted with meditators, as well as participant observation at meditation retreats and local practice groups. The article explores how these two articulations of Vipassana and Mindfulness allow practitioners to reconfigure how they perform their bodies and selves, leaning towards versions of subjectivity that contrast with paradigmatic versions of the modern self. It suggests that the ontological politics of meditation are multiple, involving a wide range of performances, effects and arrangements, requiring social scientists to take into account how meditation unfolds in practice in order to avoid totalizing generalizations.
\end{abstract}

\section{Keywords}

affect, Mindfulness, ontological politics, social studies of meditation, Vipassana 


\section{Introduction}

The popularization of meditation in the West has generated a substantial amount of scholarly work within the social sciences. Social studies of meditation (SSM) are characterized by two conflicting approaches: on the one hand, we face a growing body of critical literature on the political aspects of meditation, arguing that these practices have been coopted by capitalism, neoliberalism and medicalization; on the other hand, studies of meditation in practice often ignore political aspects and frequently follow a humanist approach.

This article draws on an empirical study of two popular forms of meditation Mindfulness and Vipassana - and aims to bridge the gap between the 'politics' and 'practice' of meditation. It does so by indexing the politics of meditation to what it can do (Deleuze, 1990) to bodies, selves and environments, i.e. as forms of ontological politics (Mol, 1999). This study develops a new way of thinking about the politics - and practice - of meditation. It analyses the ways in which practices of meditation reshape subjectivities, calling for a turn to ontology in SSM. This turn to ontology allows SSM to: avoid reducing meditation to yet another expression of broader social forces neoliberalism, modernity, medicalization - focusing instead on the environments, associations and performances put in place by meditation to reshape subjectivities; rethink the political aspects of meditation as linked to the ways in which bodies and selves are reconfigured in practice, i.e. as ontological politics that enact particular versions of subjectivity.

The following sections delve into current literature within SSM, focusing on critical studies of meditation and on studies of meditation in practice, unpacking the ontological approach developed in this article and reflecting on how it can help social scientists to rethink the politics and practice of meditation.

\section{Critical studies of meditation}

Critical approaches suggest that meditation is an expression of broader social forces, aligned with previous critiques of contemporary spirituality (Carrette \& King, 2005). Mindfulness, a secular form of meditation, has been characterized as the new opiate of the masses (Dawson \& Turnbull, 2006) and a driver of therapeutic surveillance and medicalization (Barker, 2014). This critique extends to non-secular practices, as Buddhism has become 'enmeshed in medical, psychological and scientific frameworks . . . removed from the realm of religion and professionalized to become the property of 
psychologists [and] doctors' (Wilson, 2014, pp. 101-103). The adaptation of Buddhist meditation to local cultures favours its appropriation by therapeutic devices and capitalism - meditation is understood as a valuable form of spiritual capital (Arat, 2016) within the framework of emotional capitalism (Illouz, 2008).

Recently, David Purser has developed a powerful critique of Mindfulness. He explored the couplings of meditation, capitalism, therapeutic cultures and science, arguing that 'mindfulness is nothing more than basic concentration training. . . . a tool of selfdiscipline disguised as self-help. . . . it helps [practitioners] adjust to the very conditions that cause their problems' (Purser, 2019, p. 5). Purser identifies some of the tenets characterizing the contemporary meditation movement - commodification, privatization and colonialism - proposing a revolutionary mindfulness that 'is unapologetically anticapitalist' (Purser, 2019, p. 87).

Critical approaches often draw on the assumption that affect is indexed to neoliberal devices of self-regulation (Papadopoulos, 2011), and laboratory studies of the meditative brain are considered emblematic to show how meditation has been appropriated by capitalism (Davies, 2015). However, as observed by Joanna Cook, critical claims are 'not borne out ethnographically' (Cook, 2016, p. 143); critical approaches are not interested in the empirical study of meditation, they repeat "what the social world is already made of' (Latour, 2005, p. 57), separating practice and politics. In order to avoid the lure of hegemonic social forces, reflections on the politics of meditation must be supported by empirical research.

\section{Studies of meditation in practice}

One of the earliest sociological studies of meditation was carried out by David Preston. Preston suggested that Zen meditation is a form of experiential learning that involves 'deconditioning of both personal and socially shared habits and processes of reality construction' (Preston, 1988, p. 73). Informed by Becker's work on marihuana (Becker, 1953), Preston argued that Zen practitioners go through various stages to become meditators: sitting properly to produce the symptoms of meditation; recognizing the symptoms as a product of sitting and attributing them a certain meaning, in order to take encouragement from them (Preston, 1981, p. 50).

More recently, it has been argued that meditation fosters embodied, non-discursive forms of reflexivity (Lea et al., 2015; Pagis, 2009), allowing subjects to become aware of the 'diverse range of conscious and unconscious ... forces that shape human action' 
(Whitehead et al., 2015, p. 559). Michal Pagis carried out an extensive ethnography on Vipassana meditation in the US and Israel that highlights the "role of the body in the production and maintenance of self' (Pagis, 2019, p. 15); although Vipassana retreats are conducted in silence, there is a constant articulation between social and inner worlds, and subjective experiences are affected by non-verbal semiotics (Pagis, 2010a, p. 325). Pagis's work emphasizes the profoundly social dimensions of Vipassana meditation, arguing that 'the meditation center is a training space in a specific kind of social order and social interaction' (Pagis, 2019, p. 98).

Stanley and Kortelainen (2019) analysed meditation from an assemblage perspective, focusing on affective-discursive practices, including conceptual, historical, metaphorical, material and bodily resources. Their approach criticizes 'the idea that mindfulness is a totalising discourse, producing the same effects everywhere it goes' (Stanley \&

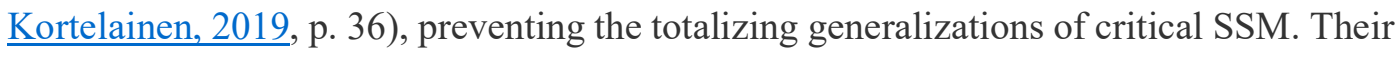
research is an important contribution to decentre SSM from critical - and humanist approaches, recognizing the importance of material and bodily dimensions for the emergence of meditative affect.

Although empirical studies of meditation often overlook political aspects, recently it has been argued that meditation may offer alternatives to the 'modern self' (Carvalho, 2014; Stanley, 2013), as well as valuable insights into the subjective aspects of the ecological crisis, allowing practitioners to become aware of the sensuous and more-thanhuman dimensions of affect (Carvalho, 2017). There are also attempts to incorporate mindfulness within methodological repertoires, triggering forms of reflexivity that take into account the body and the senses (Stanley, 2013; Whitehead et al., 2015). This indicates that there is a growing concern with the ways in which meditation reshapes subjectivities, methodologies and politics. The ontological approach developed in this article argues that the normative and political aspects of meditation are indexed to the ways in which bodies and selves are reshaped, suggesting that meditative affect emerges through specific performances and ways of engaging with environments and non-humans.

\section{An ontological approach to meditation}

As we have seen, SSM are characterized by a divide. On the one hand, critical perspectives present meditation as an expression of already existing social forces capitalism, neoliberalism, medicalization. On the other hand, studies of meditation in practice frequently ignore political aspects and often follow a humanist standpoint, 
focusing on issues of social construction and interaction. In both cases, critical and humanist sociology has the upper hand.

The ontological approach offers a new way of analysing meditation in practice and of thinking about its politics. First, it attends to the ways in which environments, couplings with non-humans, bodies and selves are reshaped to produce meditative subjectivities, in contrast to humanist standpoints; second, it conceptualizes the politics of meditation as linked to the specific versions of subjectivities and bodies that it can produce, avoiding totalizing generalizations and recognizing the political - and ontological-multiplicity of meditation.

The approach developed in this article is informed by the concept of 'ontological politics', popularized by Annemarie Mol. In the article 'Ontological politics: A word and some questions', Mol (1999) tells us a story about anaemia. Her argument is that specific practices produce different versions of anaemia - clinical, statistical and pathophysiological - and that each performance ends up diagnosing 'something different', as the 'objects of each of the various diagnostic techniques do not necessarily overlap with those of the others' (Mol, 1999, p. 78). Mol stresses that her approach indicates that reality is multiple, not merely plural, as particular performances bring forward certain versions of disease and reality - her 'emphasis on ontological transformation pointed to changes in the very composition of the world' (Gad \& Jensen, $\underline{2014}$, p. 702). As Mol wrote,

If the term 'ontology' is combined with that of 'politics' then this suggests that the conditions of possibility are not given. That reality does not precede the mundane practices in which we interact with it, but is rather shaped within these practices. So the term politics works to underline . . this process of shaping, and the fact that its character is both open and contested. (Mol, 1999, p. 75)

Drawing on Mol's work, the ontological approach recognizes the open, multiple and contested character of meditation, as well as the fact that meditative subjectivities are not given a priori, but are entangled with specific performances, environments and associations that enact certain versions of bodies and selves. As we will see, the two schools of meditation that will be analysed - Vipassana and Mindfulness - perform subjectivities that contrast with the paradigmatic modern self (Pickering, 2010). However, this does not necessarily apply to other forms of meditation, indicating that its politics are deeply entwined with particular performances, associations and the sites in 
which it enfolds, reminding us that we should refrain from generalizing meditation as a whole but rather attend to how it is enacted in practice.

Another important concept to operationalize the ontological approach is meditative affect, understood as an energy that 'has the capacity for producing changes in individual and even collective human . . . conduct' (Philo et al., 2015, p. 41). In this article I argue that meditative affect is not confined to individual subjectivities but is rather indexed to a set of practices, environments and associations. The ontological approach is informed by scholarly work that recognizes that affect is a more-than-human, autonomous and collective intensity emerging through the relational becomings of bodies and mediations (Anderson, 2014; Harrison, 2000; Massumi, 1995). Affect, in this sense, can be understood as a 'pre-individual intensity or force' (Bollmer, 2014, p. 317) that resists stabilization and containment (Coleman, 2017), and is entwined with heterogeneous assemblages that perform meditation in practice, entailing particular techniques, performances, associations and environments.

The turn to ontology in SSM emphasizes the ways in which meditative affect emerges in practice through specific associations with non-humans and performances, and understands the politics of meditation as linked to the enactment of specific versions of bodies and selves. It shows the importance of focusing on meditation in practice, instead of taking for granted pre-existing social forces, as in critical SSM; it recognizes that meditative affect is not a given phenomenon, but rather depends on heterogeneous couplings between humans, environments and non-humans to be enacted, potentially producing different kinds of subjectivities; it allows us to tackle the political aspects of meditation as indexed to the particular bodies and selves produced by these practices, thus avoiding the universalizing generalizations that characterize critical SSM, recognizing the multiplicity of meditation and its politics.

\section{Methodology}

This article relies on empirical data stemming from $\mathrm{PhD}$ research conducted between 2009 and 2013. The PhD - in Sociology - aimed to address two research questions: How does meditation bring forth new versions of subjectivity? What are the ontological politics of these practices of meditation? Two case studies were selected based on their popularity and the fact that their courses (residential retreats) were available to lay students in

Europe, where fieldwork was conducted. As a graduate student with no previous experience with meditation, these residential courses were an opportunity to conduct 
empirical research, analysing how particular arrangements are assembled to allow the emergence of specific versions of subjectivity. My own experiences were useful to reflect on the clash between meditative and non-meditative subjectivities. The methodology that underpinned this research combined ethnographic and phenomenological approaches, and was informed by scholarship within Science and Technology Studies on the couplings of human and non-human agency, focusing on how various performative and environmental rearrangements reshape subjectivities.

The first case study is Vipassana meditation in the tradition of S. N. Goenka (1924-2013). This tradition is linked to Theravada Buddhism (the only surviving school of a group of schools which was called Hinayana), belonging to the orthodox forms of Buddhism in Burma, Thailand, Laos, Cambodia and East Pakistan (Rahula, 1959, p. viii). Goenka, who initially worked as a businessman, started practising Vipassana during the 1950s with U Ba Khin (a layman) of Burma, and in 1969 he led his first 10-day course in India. In 1979, Goenka started teaching in different locations around the globe (Goenka, 1998, pp. viiviii). Nowadays, there are approximately 120 Vipassana centres worldwide and it is estimated that more than 100,000 people attend these courses every year. Vipassana is focused on the detached observation of physical sensations - its flagship technique is a body scan where participants scan/sweep their bodies from head to toe, feeling various sensations with equanimity (instead of identifying with them). Students learn Vipassana through a 10-day residential course that is emblematic to explore the performative, spatial and material reconfigurations enrolled by practices of meditation.

The second case study concerns the set of practices of Mindfulness taught by Thich Nhat Hanh. Born in central Vietnam in 1926, he was ordained as a Buddhist monk at the age of 16 - his teacher was the Zen master Thich Chan That, belonging to a Zen school that includes both Theravada and Mahayana traditions (Chapman, 2007, p. 299). Thich Nhat Hanh (Thay, to his students) was heavily involved in peaceful protests and social action during the civil war in Vietnam and after a stay in the US he was refused permission to return to his country (Hanh, 1995, p. xii). He founded the Plum Village Monastery, located near Bordeaux, France, in 1982, attracting thousands of visitors since then. Thay is the main proponent of engaged Buddhism, 'a contemporary form of Buddhism that engages actively yet nonviolently with the social, economic, political, social and ecological problems of society' (King, 2009, p. 1). It entails not only social engagement but also means that Mindfulness - moment to moment awareness - is applied to everyday life. 
Between 2010 and 2013 I attended two 10-day Vipassana retreats (in Portugal and the UK) as well as two retreats in Plum Village (a one-week retreat and a two-week retreat) and meetings of local meditation groups linked to these traditions in Exeter, UK, where I carried out participant observation. Twenty-four semi-structured interviews were conducted with practitioners of these traditions. Since Vipassana retreats are conducted in silence, I contacted potential interviewees on the final day (when noble silence is lifted), and face-to-face and phone interviews were carried out afterwards. I also conducted some interviews in Plum Village with fellow retreat participants. In both cases (Vipassana and Plum Village retreats) there is gender segregation, i.e. there are specific retreat (and living) spaces for males and females. This meant that the majority of interviewees were male - female interviewees were mostly contacted through local meditation groups. Although the sample includes a wide range of nationalities, most participants were European and North American, white, with university level education and between 28 and 60 years old. My own experiences with these practices - recorded in a field diary - were useful to understand some of the phenomenological aspects involved. All interviews were fully recorded, transcribed and anonymized.

The empirical sections draw on ethnographic notes, quotes from semi-structured interviews and my own experiences to analyse the ontological politics of meditation: the set of arrangements, performances and associations put forward by Vipassana and Mindfulness to enact certain versions of subjectivity; the ways in which these versions of subjectivity lean towards particular ways of enacting bodies and selves and engaging with environments and non-humans. In summary, the empirical sections cover two main aspects: first, the description of how meditative subjectivities are performed, taking into account non-human agency, environments and particular performative reconfigurations, avoiding the humanist idiom that characterizes SSM; second, the normative and political dimensions of meditation, understood not as the expression of hegemonic social forces but as stemming from what meditation can do, i.e. the potential of meditative affect to perform specific versions of bodies and selves.

Meditation is not a homogeneous practice - it involves different traditions, philosophies and schools. These two case studies are specific articulations of meditation, involving particular versions of subjectivities, bodies and selves, as well as distinct practices, environments, human and non-human couplings. Therefore, and although, as we will see in the empirical sections, in the case of these two practices of meditation it could be argued that they enact versions of subjectivity that contrast with the paradigmatic modern 
self, these findings should not be generalized to other types of meditation. In fact, they are specific to these particular forms of Vipassana and Mindfulness, as meditation is not a universal phenomenon but rather involves multiple articulations, ontological politics and forms of affect.

\section{Environments and non-humans}

This empirical section focuses on how these two practices of meditation entail new ways of engaging with environments and non-humans in order to bring to the fore particular versions of subjectivity. Participants are introduced to Mindfulness and Vipassana by attending meditation retreats. Following an ontological approach, we can look at meditation retreats as arrangements that disrupt everyday life by introducing specific schedules, regulations, performances and new ways of attending to the self in order to enact meditative affect. As Fitzgerald et al. argued, there is a 'matrix of transactions between urban life and the always-developing, malleable brains of urban citizens' (2016, p. 223) - subjectivities and affect are entwined with everyday environments and associations with non-humans. The meditation retreat reconfigures regular environments and associations with non-humans, aiming to enact particular versions of subjectivity that contrast with everyday, urban life.

The laboratory is a recurrent metaphor within SSM (Pagis, 2010b; Stanley \& Kortelainen, 2019; Tresch, 2011). As put by Pagis: 'Like laboratories, meditation centers are places where the complexities of life can be put aside in order to analyze self and reality in a relatively "sterile" environment' (Pagis, 2010b, p. 484). Meditation retreats are portable, transferable and potent assemblages (Stanley \& Kortelainen, 2019) that disrupt regular associations with non-humans - participants are introduced to bells, cushions and benches, and rely on them to perform meditative affect. These devices are key to enacting new forms of affect, and are "patterned into a relational topology of senses, movements, rhythms, and affective action' (Holloway, 2003, p. 1967).

The laboratory metaphor is interesting to emphasize the contrast with everyday, city life - both Vipassana and Mindfulness retreats are conducted in rural areas. In the case of Vipassana retreats, there is a reduction of environmental stimuli. Participants can spend more than 10 hours practising meditation each day; they are not allowed to talk during retreats; meditative spaces, such as the main meditation hall, have reduced lighting; meditators are advised to wear simple clothes to avoid distractions; there are individual cells (supporting sensory deprivation) that can be used by more experienced students - 
consisting of a couple of cushions in a very small room. When it comes to environments and non-humans, Vipassana aims at reducing external stimuli - sensory deprivation becomes a strategy to enact meditative affect, allowing participants to directly face mental rumination: as most interviewees mentioned, as soon as they sit cross legged and start meditating the mind becomes agitated and is flooded with different thoughts, requiring them to turn their attention to the breath and the body.

Retreats in the tradition of Thich Nhat Hanh also rely on the reconfiguration of habitual environments - and couplings with non-humans - to enact particular versions of subjectivity, but the strategy is different: the aim is not to reduce sensory stimuli but to actively rely on the environment as a driver of meditative affect. Retreats in this tradition are, according to some interviewees, a 'laboratory for new ways of life', relying on a strategy that could be coined as 'material-semiotic' (Law, 2008), as subjects learn to draw on environmental devices and specific non-humans to enact meditative affect. The most emblematic example pertaining to this ontological reconfiguration has to do with the mindfulness bell. Physical bells - of various sizes - are widely distributed at Plum Village. Participants are instructed to stop whatever they are doing and breathe mindfully, in silence, three times, when they hear its sound. Bells allow participants to enact meditative affect, indicating that in the context of retreats certain materials 'have a situated consistency', conditioned by 'how they are held together' and 'grasped as an event' that 'resists entrainment, structuration, and inscription' (Doel \& Segrott, 2004, p. 730). While meditative affect can be enacted by physical bells, during their daily lives participants should be able to rely on the environment as a driver of Mindfulness - in those situations, meditative affect is enacted by what practitioners describe as metaphorical bells. The following example, shared by a long-term practitioner, is particularly emblematic:

I find the metaphorical bells that we have in our daily lives very important . . The other day I was rushing around at work and I didn't have much time for lunch . . . I wasn't being very mindful, and returning back from the sandwich shop to my office I walked through a churchyard . . . I saw some cherry trees which were in blossom, and that was a bell of mindfulness to me, because it stopped me . . . and that made me think ... what I am doing rushing when I'm eating, and that made me stop and sit on the wall by the churchyard and I just watched the trees for about five minutes . . . it stopped me in the middle of my rush, and unmindful state, and 
allowed me to slow down and gain a perspective and space. (Interview, Michael, May 2011)

This quote indicates that participants are able to rely on the environment to enact meditative affect. In this case, cherry trees became material-semiotic devices that allowed this practitioner to switch to a meditative state - according to him, he 'wasn't being very mindfulness', indicating that he wasn't performing meditation but was in an 'unmindful state', characterized by 'rush'. This reinforces the more-than-human and decentred dimensions of affect (Manning, 2010), indicating that meditative modes of subjectivity are not pre-given but rely on the establishment of certain performances and associations with non-humans (in this specific case cherry trees, but participants refer a wide range of examples, such as traffic lights or church bells). This quote also suggests that the 'unmindful state' described by Michael stemmed from the pace of his job and city life the rhythms of the polis are not conductive to meditative affect, and the practitioner actively had to rely on particular associations with non-humans to enact a meditative version of subjectivity.

These examples indicate that meditative affect is enacted by rearranging regular engagements with environments and non-humans. The meditation retreat can be understood as a technology that not only disrupts these everyday, pre-meditative arrangements but allows participants to develop the ability to turn their daily environments into drivers of meditative affect. This can happen by resorting to mindfulness bells or, in the case of Vipassana, by setting up a domestic space for sitting meditation, often with reduced lighting, cushions and other meditative paraphernalia, in order to recreate the retreat environment. The ontological politics of meditation thus imply a rearrangement of regular engagements with environments and non-humans, enacting different versions of the body, as we will see in the following section.

\section{Meditative bodies}

This section is focused on a key aspect of the ontological politics of meditation: the ways in which Vipassana and Mindfulness require practitioners to attend to their bodies in particular ways in order to trigger meditative affect. Practices of meditation rely on specific performative configurations that aim at enacting a new version of the body through the training of attention, particular postures and movements. These reconfigurations turn the body into a privileged site of meditative affect, with 
interviewees often reporting that meditation reshapes how they feel their bodies, both in the context of retreats and throughout daily life.

The meditative body is enacted through a set of performative reconfigurations. In the case of Vipassana, one has to sit straight, with the eyes closed, focusing on how the breath touches the nostrils. The practice then progresses into a body scan from head to toes. One starts from the top of the head, scanning every body part at the surface. After some days, retreat participants scan the body top down and bottom up. Participants are instructed to observe these various sensations with equanimity: 'one is aware of all that one experiences, of every sensation, but does not react' (Goenka, 1987, p. 19). While scanning the body, practitioners should not react to sensations, whether positive or negative, detaching from the unending flow of thoughts.

Mindfulness in the tradition of Thich Nhat Hanh entails a wide range of practices that go beyond sitting meditation. The aim is to turn everyday life into an opportunity to practise meditation - this includes formal practices such as sitting and walking meditation, but also ways of turning activities such as washing the dishes or brushing the teeth as forms of meditation, constituting a form of engaged Buddhism. There are three aspects at stake: first, in order to avoid mind-wandering, participants should focus on their bodies - during walking meditation participants are instructed to concentrate on their feet touching the floor; second, meditators are instructed to slow down - for instance, while practising eating meditation practitioners should become aware of all the movements involved, such as chewing and swallowing; third, the breath works as an anchor to bring practitioners back to their bodies, helping them focus on the task at hand.

A long-term practitioner mentioned that the essence of Mindfulness is to come back to the body, allowing her to anchor her monkey mind (an expression related to mindwandering):

... the practice of Mindfulness always has to start with my body, because, again, my mind runs often . . . a way of anchoring my mind, my monkey, is always to come back to my body, into my bones, feeling my bottom on the floor, my feet on the floor, it's continually coming back to that, I mean, I would say that's what for me is the essence of this practice, it's very practical. (Interview, Jane, April 2011) According to this participant, the body anchors the mind, i.e. it rescues participants from mind-wandering, the unending flow of thoughts that characterizes non-meditative subjectivities. But, according to interviewees, meditation goes beyond coming back the body; in fact, a new version of the body is enacted, illustrating the ontological capacity 
of meditation. While focusing on the body, practitioners report that it starts displaying new properties, often described as pins and needles, tingling, vibrations and warmth. The following quote suggests that the continuous practice of Vipassana enacts a different version of the body:

... the more you practise the more sensitive your corporeal sensations become . . . you begin feeling a very kind of pins and needles type of energy . . . it's not exactly like pins and needles, but it's a similar kind of tingling . . . subtle sensations . . . as you progress and refine this state you start feeling your physical body as kind of dissolving into more of a kind of . . . for lack of a better word . . . a kind of energetic tingling . . . and then when you kind of fully feel this state, you begin to be able to maintain this for longer and longer periods of time, you can constantly feel this whole body tingling with this kind of electric subtle sensations, and then you start penetrating internally until you actually begin to feel certain organs or shape, mass of certain organs, at least ... which is an interesting sensation. (Interview, Tim, December 2011)

This quote suggests that the practice of Vipassana performs a new version of the body. The felt body progressively turns into a set of subtle sensations, and some practitioners reported feeling their bodies dissolve into vibrations. This heightened experience of corporeal sensations indicates that, similarly to Mol's (1999) different medical practices, Vipassana performs bodies that differ from their non-meditative versions. Practitioners also mentioned that, during everyday life, they often resort to subtle sensations - or vibrations - to deal with difficult episodes (easily found on the palms of the hands), relying on meditative affect to switch from non-meditative to meditative states what Pagis (2009) calls embodied self-reflexivity. Meditative affect reshapes the body a practitioner mentioned that, since he started practising meditation, his body provides him with a sense of comfort, warmth and softness, and there is a particular body part the hands - where he can easily experience this 'warmth':

... a big part of this practice is coming back to your body . . . inhabiting the body . . . I started to feel more comfortable in my body and also a kind of warmth, so ... it's quite a nice place to dwell . . . if I let my tension rest and my . . . and my hands for instance . . . there's a kind of softness and a warmth and a . . like a . . . a well-being that comes from that. (Interview, Steve, December 2011)

This particular interviewee mentioned that, for him, the practice of Mindfulness was a lifelong progress of releasing tension stored in the body, gradually learning how to turn 
it into a source of warmth, energy and well-being. Some practitioners reported that meditation allowed them to realize that some of the corporeal sensations enacted by meditation were not necessarily 'theirs'. They became aware of patterns - and sensations - beyond their individual selfhood, often mentioning ancestors and family members, suggesting that meditative affect challenges 'strict boundaries and separations between the historical and the personal, the psychological and the social and the material and immaterial' (Blackman, 2016, p. 269). In that sense, this heightened awareness of the body is often coupled with the ability to experience affect as porous, decentred and not bound to self-contained individuality. The following quote, shared by an advanced Vipassana practitioner who works as a teacher, is a good illustration of how the experience of the body is reshaped by meditation:

Yeah, with my students sometimes I will get aware of certain sensations coming up, if they're stressed or . . . it's like a bit if I'm getting an early warning signal of how they might be feeling, or if some anger is coming up. I think it's a bit of like a tuning for vibrating, you can sort of like get other people's vibrations, and then a sensation comes and you're like hum . . . all different types of sensations can come. (Interview, Rebecca, April 2012)

This excerpt suggests that the Vipassana body is porous, consisting of a set of vibrations that challenge the boundaries between self and non-self. In this case, the participant draws on the experience of vibrations - the corporeal sensation frequently described by advanced practitioners - to become aware of other people's sensations, namely her students. The ontological politics of Vipassana thus turn the body into 'an event for affective resonance' (Manning, 2010, p. 124), indicating that it performs versions of subjectivity that clash with self-contained versions of the self, an aspect that will be explored in more detail in the following section.

\section{Meditation and the self}

The ontological politics of Vipassana and Mindfulness entail particular ways of attending to the self, leading to versions of subjectivity characterized by the awareness of habit patterns; the ability of not reacting automatically to those habits; the emergence of decentred forms of self that contrast with modern selfhood. As we have seen in previous sections, these practices of meditation are characterized by performative reconfigurations that transform the ways in which participants deal with corporeal and environmental 
stimuli. By enacting these performative reconfigurations, participants become gradually aware of their regular habit patterns. As put by a practitioner:

... you start seeing into patterns . . . you see certain automatic responses to certain situations become more clear, and I think that's insight, gaining access to these almost unconscious conditionings, and being able to sort of get that much of mindfulness into our awareness. (Interview, Brad, February 2011)

This interviewee mentioned 'unconscious conditionings', referring to Mindfulness as a way of bringing awareness into those patterns - in fact, 'meditation sets up an expansive sense of awareness in order to be more accepting of the body-mind as it is' (Lea et al., $\underline{2015}$, p. 56). Vipassana and Mindfulness allow practitioners to observe their premeditative habits, while striving to performatively deal with stimuli with equanimity/mindfulness, instead of reacting. As put by a Vipassana meditator:

Meditation allows me to observe my own habits. If I know the habit I can break it. It's about how you treat that sensation (to transform the mind), observing the habits of how to treat the sensation. It's about how we think, how we create reality. (Interview, Irina, September 2012)

Irina's words indicate that treating sensations with equanimity allows practitioners to observe - and eventually break - certain habit patterns. This interviewee also mentioned that meditation is about 'how we create reality', reinforcing its ontological capacity. Throughout everyday life, practitioners rely on Vipassana and Mindfulness to deal with a wide range of phenomena, shaping the ways in which they engage with sensations, environments, other humans and non-humans. Participants mentioned that, by becoming aware of their habit patterns, they often gained a sense of spaciousness and freedom, instead of feeling the urge to react automatically. Interviewees also reported that these habit patterns were not necessarily individual, sometimes highlighting their intergenerational dimensions, reinforcing the pre-personal and decentred characteristics of affect (Anderson, 2009). According to interviewees, practices of meditation gave them the freedom to choose how to respond to habit patterns:

It [Mindfulness] slowed down my reactions to things, I don't immediately do stuff out of habit or just very direct reaction, you know, like this happens automatically, almost like a robot, I feel more in control of myself because when things happen I see I have a desire and an energy that is pushing me in a certain direction . . . and I see that it's there, and then I can either follow it or not. (Interview, Neil, February 2011) 
Interviewees used concepts such as spaciousness, freedom and control to characterize this process. As observed by Whitehead et al. (2015, p. 557), meditators become 'more aware of the forces that shape their embodied experience and drive subsequent reactions'. Vipassana and Mindfulness allow participants to observe the objects of meditation (such as sensations and thoughts) without immediately reacting to them, and this applies to everyday life events. As an interviewee told me, someone who is not going to react to body sensations is also not going to blindly react to someone honking in traffic. Participants also reported changes in their sense of self, i.e. namely the fact that they became less attached to a strong, self-contained sense of individuality. Some interviewees mentioned that meditation allowed them to become more receptive to vulnerability, extending their awareness to the fact that reality is impermanent and that there are no fixed boundaries between self and non-self. According to a Mindfulness practitioner, this gradual change in the sense of self initially manifested by realizing that the self-image he was so attached to was, in fact, a fantasy:

I started observing in my thought patterns things that didn't accord with my . . . with the image I had of myself . . so the image was actually . . just . . . it was made up, it was a kind of a fantasy. I started to see lots of things that I wasn't able to see before, because it didn't accord with this image I had of myself. (Interview, Sean, February 2011)

This change in self-perception is part of a gradual process of de-identifying with a stable, bounded and self-contained sense of self - the modern self. The ontological politics of these forms of meditation lean towards a decentred version of subjectivity, allowing practitioners to progressively de-identify with their flow of thoughts, assuming the role of conscious observer. As put by an advanced Vipassana practitioner:

... what happens is that you become dis-identified with your patterns of thought, so instead of leaning towards them you're practising a kind of stepping back . . . meditation as stepping into the place of the observer which is outside the notion of self . . . learning how to connect directly with reflexivity as an inherent aspect of consciousness and to dis-identify that aspect from the notion of selfhood . . . you start seeing some thought patterns that you have stuck inside from a less identified perspective, which means that you can see them much more objectively. And from that, the insight arises. (Interview, Tim, December 2011)

According to this participant, by 'stepping into the place of the observer' one disidentifies consciousness (observation) from selfhood. This leads to a de-identification 
with a self-contained sense of self, enacting ontologies - such as impermanence and interdependence - that clash with non-meditative versions of subjectivity. This process also challenges the boundaries between conscious/unconscious. While these practices of meditation allow subjects to become aware of deep-rooted habit patterns, meditative affect is indexed to non-human and a-subjective forces (that could be coined as 'unconscious'); instead of attempting to 'control' these forces (thus reinforcing individual agency), meditative affect allows practitioners to become aware of the impermanence and interdependence of 'their' selves.

Some of most dramatic and transformative experiences shared by interviewees allude to the suspension of a stable sense of self. The following excerpt stems from an interview conducted with a serious meditator (with more than 30 years of regular practice) who follows the tradition of Thich Nhat Hanh. While describing some of his most profound experiences, he suggested that Mindfulness can challenge the boundaries between self and non-self:

... the mind is an open space, formless, but at the same time it has a quality of selfawareness, it has the ability to experience that same absence of form, and that is the discovery of the deepest nature of the mind . . . that is what I think is one of the most interesting experiences that meditation can offer us. In that experience . . . we directly verify that there is no dualism between subject and object, that there is no separation between mind and what it perceives, there is no observer and observed as isolated entities, there is a nondual experience. One has the experience that the world is inseparable from consciousness. (Interview, Peter, May 2013)

When I interviewed Peter I tried to obtain more details about the practical and embodied aspects of his nondual experiences. However, and while recognizing that those episodes can be quite blissful - and even pleasurable - he reminded me that they can also generate attachment, as the mind might cling to extraordinary experiences, thus reinforcing the ego. Nevertheless, advanced practitioners of Vipassana and Mindfulness reported experiences that indicate the capacity of these practices to disrupt boundaries between observer and observed, mind and non-mind, subject and object. In that sense, these two practices of meditation can suspend paradigmatic versions of the modern self (Carvalho, 2017), allowing practitioners - especially advanced ones - to occasionally experience episodes that can be characterized by notions such as impermanence, interdependence and non-self, often framed according to the vocabulary of these two schools of meditation. 


\section{Conclusion}

This article developed an ontological approach to study meditation in practice. It drew on empirical data - participant observation at retreats and semi-structured interviews - to analyse how two schools of meditation - Vipassana in the tradition and S. N. Goenka and Mindfulness, according to the teachings of Thich Nhat Hanh - reconfigure bodies and selves, and how they draw on particular engagements with environments, non-humans and specific performances to generate meditative affect. In the case of these two traditions, we can argue that they lean towards versions of subjectivity that contrast with the paradigmatic modern self, often challenging dualist distinctions between subjects and environments, enacting porous and impermanent bodies and allowing meditators to deidentify with a stable sense of self. However, one should bear in mind that these findings are specific to these two traditions, and may not be applicable to other forms of meditation - since meditation is multiple, and not a homogeneous practice, its ontological politics cannot be decoupled from the set of material, performative and environmental arrangements that enact meditative affect.

In fact, the two case studies - Vipassana and Mindfulness - are different versions of meditation, highlighting that we are dealing with a multiple object that can involve a wide range of practices, effects and arrangements. Although, in both cases, we are met with decentred versions of subjectivity that contrast with the paradigmatic modern self, further empirical research would be needed in order to examine the specific forms of selfhood and bodies that could be enacted if these techniques were implemented in different contexts and relying on a different data set. In that sense, the ontological politics of Vipassana and Mindfulness presented here should be not be generalized - as it often done in critical SSM - and may contrast with other enactments of meditation in a wide range of settings, contexts and environments.

The ontological approach developed in this article has methodological and normative implications for SSM. First, it departs from the humanist idiom characterizing the majority of empirical studies of meditation, focusing instead on how meditative affect is enacted by particular associations with environments, non-humans and specific performative reconfigurations; second, instead of indexing the politics of meditation to hegemonic social forces - modernization, capitalism, neoliberalism - it relies on the notion of ontological politics to attend to the emergence of particular versions of subjectivity, exploring what specific articulations of meditation can do to bodies, selves and environments through a wide range of practices and associations. 
As directions for future research, the ontological approach developed in this article could be used to analyse articulations of meditation across different contexts, sites and practices, analysing the distinct versions of subjectivity that can be produced by meditation in workplaces, schools, corporations and the wellness industry. Recognizing that meditation is multiple, selecting case studies outside the Vipassana and Buddhist mindfulness contexts could have resulted in radically different versions of bodies and selves. In the future, the ontological approach could be mobilized to assess how specific institutional settings, technologies, sites and associations perform meditation, and how these particular articulations of meditation are unfolded to generate forms of affect, purposes and applications whose ontological politics may significantly contrast with those examined in this article.

\section{Acknowledgements}

I am deeply grateful to Andrew Pickering for his critical feedback throughout the years and for believing in my research from the very start. Gerald Taylor Aiken and Irina Velicu provided me with very insightful comments on a previous draft of this article. The comments shared by three anonymous reviewers were extremely helpful, and I would like to thank Reviewer 1 in particular for the fantastic feedback, encouragement and suggestions for future research.

\section{Funding}

This research was funded by the Portuguese Foundation for Science and Technology (SFRH/BD/62928/2009).

\section{References}

Anderson, B. (2009). Affective atmospheres. Emotion, Space and Society, 2(1), 77-81.

Anderson, B. (2014). Encountering affect. Routledge.

Arat, A. (2016). Practice makes perfect: Meditation and the exchange of spiritual capital. Journal of Contemporary Religion, 31(2), 269-280.

Barker, K. (2014). Mindfulness meditation: Do-it-yourself medicalization of every moment. Social Science \& Medicine, 106(1), 168-176.

Becker, H. S. (1953). Becoming a marihuana user. American Journal of Sociology, 59(3), $235-242$. 
Blackman, L. (2016). The challenges of new bio psycho socialities: Hearing voices, trauma, epigenetics and mediated perception. The Sociological Review, 64(1), 256-273.

Bollmer, G. D. (2014). Pathologies of affect: The 'new wounded' and the politics of ontology. Cultural Studies, 28(2), 298-326.

Carrette, J., \& King, R. (2005). Selling spirituality: The silent takeover of religion. Routledge.

Carvalho, A. (2014). Subjectivity, ecology and meditation: Performing interconnectedness. Subjectivity, 7(2), 131-150.

Carvalho, A. (2017). Ecologies of the self in practice: Meditation, affect and ecosophy. Geografiska Annaler: Series B, Human Geography, 99(2), 207-222.

Chapman, J. (2007). The 2005 pilgrimage and return to Vietnam of exiled Zen master Thich Nhat Hanh. In P. Taylor (Ed.), Modernity and re-enchantment: Religion in postrevolutionary Vietnam (pp. 297-341). Institute of Southeast Asian Studies.

Coleman, R. (2017). A sensory sociology of the future: Affect, hope and inventive methodologies. The Sociological Review, 65(3), 525-543.

Cook, J. (2016). Mindful in Westminster: The politics of meditation and the limits of neoliberal critique. HAU: Journal of Ethnographic Theory, 6(1), 141-161.

Davies, W. (2015). The happiness industry. Verso.

Dawson, G., \& Turnbull, L. (2006). Is mindfulness the new opiate of the masses? Critical reflections from a Buddhist perspective. Psychotherapy in Australia, 12(4), 60-64.

Deleuze, G. (1990). Expressionism in philosophy: Spinoza. Zone Books.

Doel, M. A., \& Segrott, J. (2004). Materializing complementary and alternative medicine: Aromatherapy, chiropractic, and Chinese herbal medicine in the UK. Geoforum, 35(6), $727-738$.

Fitzgerald, D., Rose, N., \& Singh, I. (2016). Living well in the Neuropolis. The Sociological Review, 64(1), 221-237.

Gad, C., \& Jensen, C. B. (2014). The promises of practice. The Sociological Review, 62(4), 698-718.

Goenka, S. N. (1987). The discourse summaries. Vipassana Research Publications.

Goenka, S. N. (1998). Satipatthana Sutta discourses by S. N. Goenka. Vipassana Research Publications.

Hanh, T. N. (1995). Peace is every step. Rider.

Harrison, P. (2000). Making sense: Embodiment and the sensibilities of the everyday. Environment and Planning D: Society and Space, 18(4), 497-517. 
Holloway, J. (2003). Make-believe: Spiritual practice, embodiment, and sacred space. Environment and Planning A, 35(11), 1961-1974.

Illouz, E. (2008). Saving the modern soul: Therapy, emotions, and the culture of self-help. University of California Press.

King, S. B. (2009). Socially engaged Buddhism. University of Hawai'i Press.

Latour, B. (2005). Reassembling the social. Oxford University Press.

Law, J. (2004). After method: Mess in social science research. Routledge.

Law, J. (2008), Actor-network theory and material semiotics. In B. S. Turner (Ed.), The new Blackwell companion to social theory (pp. 141-158). Blackwell.

Lea, J., Cadman, L., \& Philo, C. (2015). Changing the habits of a lifetime? Mindfulness meditation and habitual geographies. Cultural Geographies, 22(1), 49-65.

Manning, E. (2010). Always more than one: The collectivity of a life. Body \& Society, $16(1), 117-127$.

Massumi, B. (1995). The autonomy of affect. Cultural Critique, 31, 83-109.

Mol, A. (1999). Ontological politics. A word and some questions. The Sociological Review, 47(1), 74-89.

Pagis, M. (2009). Embodied self-reflexivity. Social Psychology Quarterly, 72(3), 265283.

Pagis, M. (2010a). Producing intersubjectivity in silence: An ethnographic study of meditation practice. Ethnography, 11(2), 309-328.

Pagis, M. (2010b). From abstract concepts to experiential knowledge: Embodying enlightenment in a meditation center. Qualitative Sociology, 33(4), 469-489.

Pagis, M. (2019). Inward: Vipassana meditation and the embodiment of the self. Chicago University Press.

Papadopoulos, D. (2011). The imaginary of plasticity: Neural embodiment, epigenetics and ecomorphs. The Sociological Review, 59(3), 432-456.

Philo, C., Cadman, L., \& Lea, J. (2015). New energy geographies: A case study of yoga, meditation and healthfulness. Journal of Medical Humanities, 36(1), 35-46.

Pickering, A. (2010). The cybernetic brain: Sketches of another future. University of Chicago Press.

Preston, D. L. (1981). Becoming a Zen practitioner. Sociological Analysis, 42(1), 47-55. Preston, D. L. (1988). The social organization of Zen practice. Cambridge University Press. 
Purser, R. (2019). McMindfulness: How mindfulness became the new capitalist spirituality. Repeater Books.

Rahula, W. (1959). What the Buddha taught. Grove Press.

Stanley, S. (2013). From discourse to awareness: Rhetoric, mindfulness, and a psychology without foundations. Theory \& Psychology, 23(1), 60-80.

Stanley, S., \& Kortelainen, I. (2019). Assembling mindful bodies: Mindfulness as a universal 'laboratory of practice'. In S. Salmenniemi, J. Nurmi, I. Perheentupa \& H. Bergroth (Eds.), Assembling therapeutics: Cultures, politics and materiality (pp. 20-42). Routledge.

Tresch, J. (2011). Experimental ethics and the science of the meditating brain. In F. Ortega \& F. Vida (Eds.), Neurocultures: Glimpses into an expanding universe (pp. 4968). Peter Lang.

Whitehead, M., Lilley, R., Howell, R., Jones, R., \& Pykett, J. (2015). (Re)Inhabiting awareness: Geography and mindfulness. Social and Cultural Geography, 17(4), 553-573. Wilson, J. (2014). Mindful America: Meditation and the mutual transformation of Buddhism and American culture. Oxford University Press. 